\title{
Palliative Radiotherapy as a Treatment for Carcinoma Invasion of the Sacrum: An Observational Case Series Study
}

\author{
FEDERICO AMPIL, GUILLERMO SANGSTER, GLORIA CALDITO, \\ TROY RICHARDS, YEN NGO, DONGHYUN KIM and QUYEN CHU \\ Departments of Radiology, Neurology and Surgery, \\ Louisiana State University Health Sciences Center, Shreveport, LA, U.S.A.
}

\begin{abstract}
Background/Aim: Radiotherapy for carcinoma invasion of the sacrum $(C I S)$ is an alternative treatment to surgery in patients with advanced, inoperable tumors or those not medically eligible for resection of the neoplasm. Herein we present an observational study of patients with imagingconfirmed CIS who were treated non-operatively with radiation. Patients and Methods: A retrospective chart review of CIS patients treated with palliative radiotherapy $(P R)$ during a 9-year period (2004-2013) was performed. Results: Six women and 13 men with an average age of 60 years took part in this study. Most patients (84\%) exhibited extrasacral metastases. Primary tumors included lung $(n=6)$, colorectal $(n=6)$, breast $(n=3)$, bladder or kidney $(n=2)$, and liver carcinoma or a tumor in an unknown primary site $(n=2)$. The mean follow-up time was 10 months with a 2-year survival rate of $9 \%$. The majority (71\%) of symptomatic patients obtained relief from pain following PR. Half of those individuals who were non-ambulatory prior to therapy regained mobility. There were no acute ill-effects or later complications after irradiation. Conclusion: Despite the small cohort and poor overall survival rate, non-operative radiation treatment is a beneficial method of palliative care in patients with CIS.
\end{abstract}

The sacral region is a major neurovascular crossroad, innervating and supplying blood to the lower part of the body (1). It also determines the functional state of delicate and complex sphincters of the rectum, bladder, and sexual organs as well as the motor, sensory, and vasomotor functions of the lower limbs (1). The sacrum is predisposed to invasion by pelvic or extrapelvic primary malignant

Correspondence to: Federico L. Ampil, MD, Division of Radiation Oncology, Louisiana State University Health Sciences Center, 1501 Kings Highway, Shreveport, Louisiana 71130 U.S.A. Tel: +1 3186264127, Fax: +1 3186263120, e-mail: fampil@1suhsc.edu

Key Words: Sacral metastases, metastatic tumor, palliative radiotherapy. tumors due to anatomic proximity or through hematogenous dissemination $(1,2)$. Metastatic disease in the sacrum is relatively uncommon, representing only $3-21 \%$ of patients with spinal metastases (3-5). The two traditional methods of local therapy for carcinoma invasion of the sacrum (CIS) are surgery and radiotherapy (2). Currently spinal stereotactic radiosurgery is gaining acceptance as another form of radiation treatment because it allows for administration of higher tumoricidal dose even for radioresistant tumors with minimal exposure of the surrounding normal tissues (2). CIS remains a clinically important source of morbidity and mortality after pelvic resection (6). The role of radiotherapy (RT) in the treatment of people suffering from cancer-related pain has been recently updated (7). However, there are only very few studies describing the radiotherapeutic effect in patients with CIS as a means of palliative care $(8,9)$. To fill this void, our collected data on this topic are presented.

\section{Patients and Methods}

A retrospective review of 19 individuals treated with RT for palliation of CIS during the study period from July 2004 to August 2013 was performed following approval of the outcome study (study \#995) by the LSU-Shreveport institutional review board. Patients were included in the study if: i) diagnosed with any type of cancer, ii) CIS was demonstrated by radioimaging (Figure 1), iii) palliative radiotherapy (PR) was administered and iv) follow-up (range 1 to 33 months) information after irradiation was available. Local irradiation was applied in the presence of extrasacral metastases $(n=16)$, in poor performance status $(n=1)$ or in the presence of significant comorbid illness $(\mathrm{n}=1)$; and in a histologically-confirmed CIS patient who had undiscovered primary lung cancer at the time of CIS diagnosis $(n=1)$. The clinical characteristics of the study cohort are summarized in Table I. The male to female ratio was $2: 1$. The age of the patients ranged from 47 to 83 years. Many individuals with extrasacral metastases $(n=16)$ also suffered some other coexisting illness $(n=12)$. Most patients exhibiting low back or radicular pain $(n=15)$ were treated with the conventional prescription dose of 30 Gy given in 10 fractions $(n=15)$. Three-dimensional conformal radiotherapy (3D CRT) (Figure 2) was practiced during the later stages of this 9-year period. This modality of RT involves an array of radiation beam 
Table I. Clinical summary of 19 patients with carcinoma invasion of the sacrum.

\begin{tabular}{|c|c|c|c|c|c|c|c|c|c|}
\hline \multirow{2}{*}{$\begin{array}{l}\text { Patient } \\
\text { No. } \\
1\end{array}$} & \multirow{2}{*}{$\begin{array}{c}\begin{array}{c}\text { Age/ } \\
\text { Gender }\end{array} \\
67 / \mathrm{F}\end{array}$} & \multirow{2}{*}{$\begin{array}{c}\begin{array}{c}\text { Primary } \\
\text { tumor }\end{array} \\
\text { Colon }\end{array}$} & \multicolumn{2}{|c|}{$\begin{array}{c}\text { Symptoms } \ddagger \\
\text { Pre- Post- treatment }\end{array}$} & \multicolumn{2}{|c|}{$\begin{array}{c}\text { Signs } \ddagger \neq \\
\text { Pre- Post- treatment }\end{array}$} & \multirow{2}{*}{$\begin{array}{c}\begin{array}{c}\text { Extrasacral } \\
\text { metastases }^{\dagger}\end{array} \\
+\end{array}$} & \multirow{2}{*}{$\begin{array}{c}\text { Other } \\
\text { illness }{ }^{\S \S}\end{array}$} & \multirow{2}{*}{$\begin{array}{c}\begin{array}{c}\text { Survival } \\
\text { (months) }\end{array} \\
(3)\end{array}$} \\
\hline & & & + & - & - & - & & & \\
\hline 2 & $55 / \mathrm{M}$ & Colon & + & - & + & + & + & + & (15) \\
\hline 3 & $50 / \mathrm{M}$ & Bladder & - & - & - & - & + & NK & (18) \\
\hline 4 & $67 / \mathrm{M}$ & Lung & - & - & + & NK & + & + & (1) \\
\hline 5 & 69/M & Lung & + & - & - & - & + & NK & (3) \\
\hline 6 & $56 / \mathrm{M}$ & Lung & + & - & - & - & + & + & (4) \\
\hline 7 & $58 / \mathrm{M}$ & Lung & + & + & + & - & - & - & (2) \\
\hline 8 & $47 / F$ & Breast & + & - & - & - & + & - & (33) Alive \\
\hline 9 & 71/M & Unknown & + & - & + & NK & + & + & (4) \\
\hline 10 & $63 / \mathrm{F}$ & Colon & + & + & - & - & - & + & (3) \\
\hline 11 & $83 / \mathrm{M}$ & Rectum & + & - & + & NK & + & + & (24) \\
\hline 12 & $68 / \mathrm{M}$ & Colon & + & + & - & - & + & + & (1) \\
\hline 13 & $59 / \mathrm{M}$ & Liver & + & - & + & - & + & + & (8) Alive \\
\hline 14 & $66 / \mathrm{M}$ & Colon & + & - & - & - & + & + & (13) Alive \\
\hline 15 & $60 / \mathrm{M}$ & Lung & + & NK & - & - & + & + & (1) \\
\hline 16 & $60 / \mathrm{F}$ & Lung & NK & NK & NK & NK & - & NK & (12) \\
\hline 17 & $71 / \mathrm{F}$ & Breast & + & - & - & - & + & + & (13) Alive \\
\hline 18 & $55 / \mathrm{F}$ & Breast & + & + & - & - & + & + & (14) Alive \\
\hline 19 & $56 / \mathrm{M}$ & Kidney & - & - & + & + & + & - & (18) \\
\hline
\end{tabular}

$\doteqdot$ Pain (Low back or radicular); $¥$ Limb paresis; ${ }^{\dagger}$ Brain, bone, lung, adrenal gland, mediastinal/retroperitoneal nodes, psoas muscle; ${ }^{\S}$ Hypertension, diabetes mellitus, benign prostatic hypertrophy, deep venous thrombosis, hepatitis C, asthma; NK, not known.

arrangements with each field shaped according to the beam's eye view around the target volume. In this way, normal tissue is optimally shielded from the primary radiation beam (9). With regards to sites of the primary malignant tumor leading to CIS, the lungs and the colorectum were the more common anatomical locations. Lower limb paresis was observed in approximately 7 of 18 patients, and urinary incontinence was seen in 1 of 18 cases.

With respect to determination of the subjective response to treatment, there were only 14 patients who were evaluable; with regards to objective response, only 4 patients could be assessed. The Kaplan-Meier product-limit method was used for plotting the survival curve; the log-rank test was applied to establish the presence of significant prognostic factors.

\section{Results}

Among the evaluable participants, complete relief from pain was noted in most symptomatic patients $(n=10)$. Of the 4 patients who were not ambulatory at diagnosis, 2 regained their ability to walk after RT. None of the ambulatory individuals developed neurological deficits following therapy and the treatment was well-tolerated by all patients with no acute ill-effects or later complications observed after irradiation.

At the time of this reporting, 5 individuals were alive, and their follow-up after therapy ranged from 9 to 33 months. The remaining 14 patients were deceased, with a survival period from 1 to 24 months. The overall survival rate at 2 years was 9\% (Figure 3). Median survival (MS) following the diagnosis of CIS was 12 months. Greater MS was

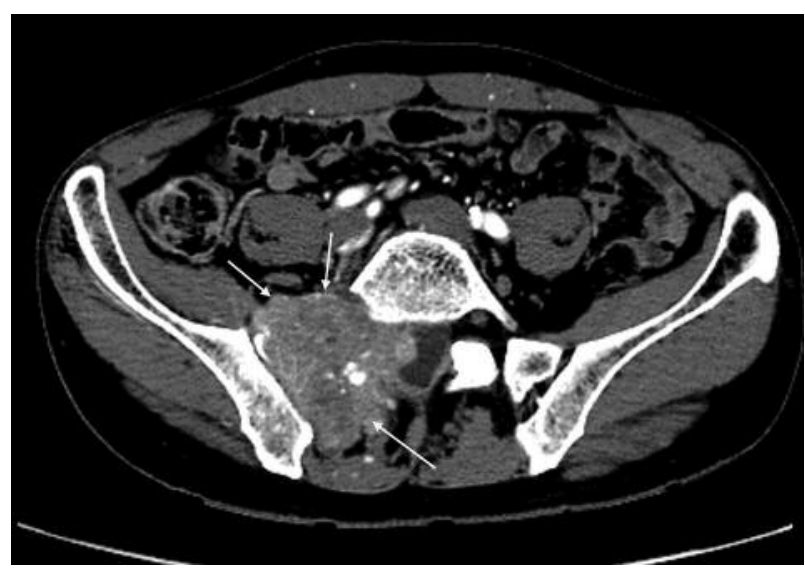

Figure 1. Axial contrast-enhanced computed tomography of the pelvis demonstrates a right paramedian soft tissue mass (yellow arrows) invading the sacrum.

documented in: i) younger versus elderly patients (15 months and 3.5 months, respectively); ii) female versus male patients (18 months and 4 months, respectively); iii) individuals with metachronous versus a synchronous presentation of CIS relative to the time of diagnosis of the primary malignant neoplasm (15 months and 3.5 months, respectively); iv) the presence versus absence of extrasacral metastases (15 months and 3 months, respectively); v) the presence versus 


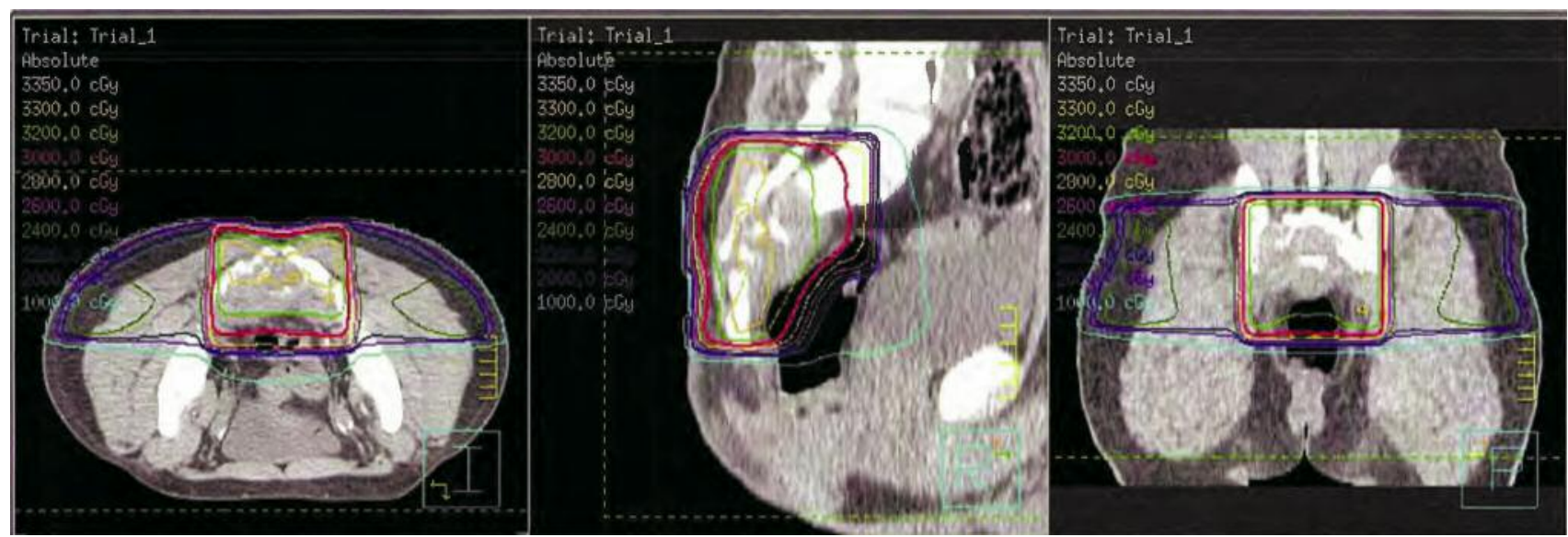

Figure 2. Computer-generated treatment plan imaging shows the conformal distribution of the prescribed radiation dose to the carcinoma invading the sacrum (as indicated by the red line, the target tumor volume is encompassed by the 3,000 cGy dose).

absence of pain (4 months and 18 months, respectively), and vi) the presence versus the absence of lower extremity weakness (15 months and 4 months, respectively). MS in the cases of a present comorbid illness or of a primary malignant tumor in the pelvic region was around 12 months or less respectively.

\section{Discussion}

Pathological processes that destroy the sacrum threaten the skeletal continuity between the spine and the lower extremities, as well as the nerve roots for which the sacrum is a conduit (10). Unfortunately, the clinical course of people with CIS is characterized by low survival rates and very poor quality of life (11). Patients may experience intractable pelvic or sciatic pain, and anal or urethral sphincter dysfunction manifested as incontinence (9). Thus, a primary goal in the management of CIS is palliation.

Surgery is the definitive treatment of choice in selected CIS patients prolonging their life expectancy. Aggressive resection is utilized mainly for treating locally advanced CIS. However, this may compromise the stability of the sacroiliac articulation, threaten the neurological state of the lower body or cause intractable pelvic girdle pain $(2,12)$. Evidently, there are serious concerns about these surgical complications. For example, if the first sacral roots are preserved, there will be no locomotion deficit; however, if transected, the patient will have plantar flexion weakness (6). In essence, morbidity can be reduced by keeping the sacral resection below the second sacral vertebra and below the sacroiliac joint (13). Survival rates of $23 \%$ to $48 \%$ after 4 or 5years following surgical treatment have been reported in cases of resectable recurrent rectal cancer involved with CIS $(6,14,15)$. On the contrary,

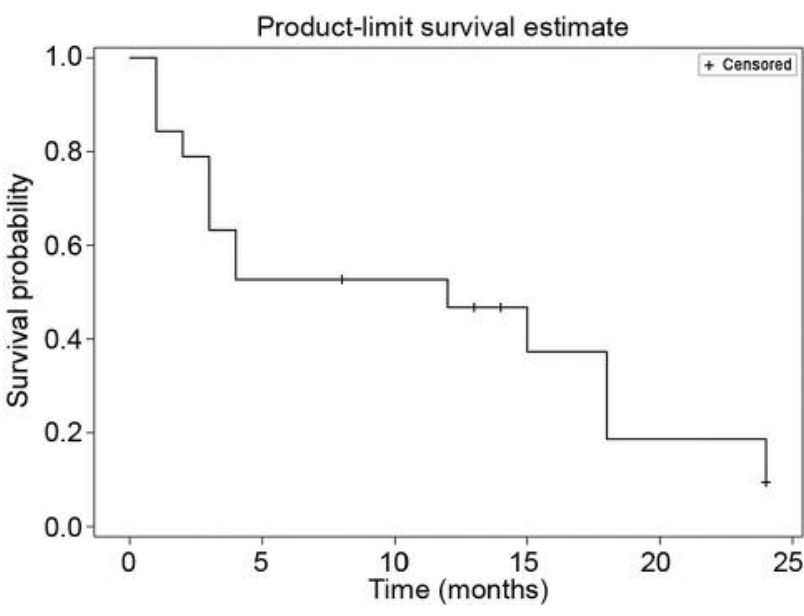

Figure 3. Overall survival of patients treated with palliative radiotherapy for carcinoma invasion of the sacrum at two years.

cases such as extensive pelvic sidewall involvement, tumor encasement of the iliac vessels, CIS extension into the sciatic notch, and proximal sacral invasion above the level of the S2S3 junction are considered contraindicative for surgical intervention (11).

With regards to the effects of using chemotherapy to treat this debilitating condition, little is known. In contrast, radiotherapy is recognized as a primary treatment for cases of inoperable CIS tumors without spinal instability where pain relief and neurological improvement are attainable (2). Because of proven efficacy in reducing the risk of normal tissue complications, 3D CRT has been the technique of choice for palliation (16). Our findings agree with the 
existing literature with respect to pelvic girdle pain palliation. However, the prognosis of life expectancy in our study is lower than the 2-year survival rates of $25 \%$ to $29 \%$ reported by other investigators $(8,17)$. Moreover, improvement of neurologic deficits has also been observed $(3,4,18)$, despite symptom relief being short-lived $(18,19)$.

The clinical investigation we are presenting here is not free of limitations. Most notably, its retrospective design and the small patient sample restrict generalization of its findings. Secondly, subjective palliation was assessed in a non-qualitative manner. Thirdly, the percentage of asymptomatic state (pain-free) during the survival period a crude indicator of quality of life - was not examined. Having said that, the quality of life in these patients requires for proper evaluation in order for the oncologist to provide the best therapeutic approach that will benefit the patient the most. Despite these limitations, observational studies should not be underestimated, especially given the infrequent occurrence of CIS. In fact, the devastating effects of untreated CIS resulting from eventual tumor invading the base of the bladder, sacral nerve roots and the pelvic floor highlight the importance of therapeutic intervention.

In conclusion, when cure is no longer a consideration, the aim of palliative therapy should be to keep the patient alive and well, out of the hospital, and with the least invasive type of treatment (20). PR deserves serious consideration whenever people are not considered "acceptable-risk" candidates for surgery. Despite the small cohort and poor overall survival rate, non-operative radiation treatment is a beneficial method of palliative care in patients with CIS. Long-term survival is possible only for a small percentage of patients.

\section{References}

1 Kollender Y, Meller I, Bickels J, Flusser G, Issakov J, Merimsky O, Marouani N, Nirkin A and Weinbroum AA: Role of adjuvant cryosurgery in intralesional treatment of sacral tumors. Results of a 3-11 year follow-up. Cancer 97: 2830-2838, 2003.

2 Quraishi NA, Giannoulis KE, Edwards K and Boszcyk BM: Management of metastatic sacral tumours. Eur Spine 21: 19841993, 2012.

3 Gerszten PC, Burton SA, Ozhasoglu C and Welch WC: Radiosurgery for spinal metastases: Clinical experience in 500 cases from a single institution. Spine 32: 193-199, 2007.

4 Maranzano E and Latini P. Effectiveness of radiation therapy without surgery in metastatic spinal cord compression: Final results from a prospective trial. Int J Radiat Oncol Biol Phys 32: 959-967, 1995.

5 Toma CD, Dominkus M, Nedelcu T, Abdolvahab F, Assadian O, Krepler P and Kotz R: Metastatic bone disease: A 36-year single centre trend-analysis of patients admitted in a tertiary orthopaedic surgical department. J Surg Oncol 96: 404-410, 2007.
6 Wanebo HJ, Antoniuk P, Koness RJ, Levy A, Vezeridis M, Cohen SI and Wrobleski DE: Pelvic resection of recurrent rectal cancer. Dis Colon Rectum 42: 1438-1448, 1999.

7 Chow E: Update on radiation treatment for cancer pain. Curr Opin Support Palliat Care 1: 11-15, 2007.

8 Dobrowsky W and Schmid AP: Radiotherapy for presacral recurrence following radical surgery for rectal carcinoma. Dis Colon Rectum 28: 917-919, 1985.

9 Gibbs IC and Chang SD: Radiosurgery and radiotherapy for sacral tumors. Neurosurg Focus 15: 1-5, 2003.

10 Hopyan S, Ngan SYK and Choong PFM: Natural history of tumour-related sacral obliteration with nerve-root preservation. Clin Oncol 17: 195-198, 2005.

11 Boyle KM, Sagar PM, Chalmers AG, Sebag-Montefiore D, Cauirns A and Eardley I: Surgery for locally recurrent rectal cancer. Dis Colon Rectum 48: 929-937, 2005.

$12 \mathrm{Du}$ Z, Guo W, Yang R, Tang X, Tao J and Li D: What is the value of surgical intervention for sacral metastases? PLoS ONE 11: e0168313, 2016.

13 Aydin C, Kayaalp C and Cetin A: Sacrectomy margins for rectal cancer invading the sacrum: An anatomic study. J Surg Oncol 103: 742-743, 2011.

14 Wells BJ, Stotland P, Ko MA, Al-Sukhni W, Wunder J, Ferguson P, Lipa J, Last L, Smioth AJ and Swallow CJ: Results of an aggressive approach to resection of locally recurrent rectal cancer. Ann Surg Oncol 14: 390-395, 2007.

15 Yamada K, Ishizawa T, Niwa K, Chuman Y and Aikou T: Pelvic exenteration and sacral resection for locally advanced primary and recurrent rectal cancer. Dis Colon Rectum 45: 1078-1084, 2002.

16 Sprave T, Verma V, Forster R, Schlampp I, Hees K, Bruckner T, Bostel T, Shafie RE, Nocolay NH, Debus J and Rief H: Quality of life and radiation-induced late toxicity following intensitymodulated versus three-dimensional conformal radiotherapy for patients with spinal bone metastases: Results of a randomized trial. AntiCancer Res 38: 4953-4960, 2018.

17 Lingareddy V, Ahmad NR and Mohiuddin M: Palliative reirradiation for recurrent rectal cancer. Int J Radiat Oncol Biol Phys 38: 785-790, 1997.

18 Wong CS, Cummings BJ, Brierly JD, Catton CN, McLean M, Catton P and Hao Y: Treatment of locally recurrent rectal carcinoma-results and prognostic factors. Int J Radiat Oncol Biol Phys 40: 427-435, 1998.

19 Pacini P, Cionini L, Pirtoli L, Ciatto S, Tucci E and Sebaste L: Symptomatic recurrences of carcinoma of the rectum and sigmoid: The influence of radiotherapy on the quality of life. Dis Colon Rectum 29: 865-868, 1986.

20 Macbeth F and Stephens R: Palliative treatment for advanced non-small cell lung cancer. Hematol Oncol Cl North Am 18: 115-130, 2004. 